\title{
Nickel and cobalt release from fidget spinners on the Danish market
}

Ahlström, Malin G.; Thyssen, Jacob P.; Menné, Torkil; Jellesen, Morten S.; Westermann, Peter J. S.; Johansen, Jeanne $D$.

Published in:

Contact Dermatitis

Link to article, DOI:

$10.1111 /$ cod. 12924

Publication date:

2018

Document Version

Peer reviewed version

Link back to DTU Orbit

Citation (APA):

Ahlström, M. G., Thyssen, J. P., Menné, T., Jellesen, M. S., Westermann, P. J. S., \& Johansen, J. D. (2018). Nickel and cobalt release from fidget spinners on the Danish market. Contact Dermatitis, 78(5), 357-359. https://doi.org/10.1111/cod.12924

\section{General rights}

Copyright and moral rights for the publications made accessible in the public portal are retained by the authors and/or other copyright owners and it is a condition of accessing publications that users recognise and abide by the legal requirements associated with these rights.

- Users may download and print one copy of any publication from the public portal for the purpose of private study or research.

- You may not further distribute the material or use it for any profit-making activity or commercial gain

- You may freely distribute the URL identifying the publication in the public portal

If you believe that this document breaches copyright please contact us providing details, and we will remove access to the work immediately and investigate your claim. 


\section{Nickel and cobalt release from fidget spinners on the Danish market}

M.G.A.: Malin G. Ahlström MD ${ }^{1}$, J.P.T.: Jacob P. Thyssen ${ }^{1}$ MD, PhD, DMSc, T.M.: Torkil Menné ${ }^{1}$ MD, PhD, DMSc, M.S.J.: Morten S. Jellesen ${ }^{2}$ MSc, P.J.S.W.: Peter J. S. Westermann ${ }^{2}$ MSc, J.D.J.: Jeanne D. Johansen ${ }^{1}$ $\mathrm{MD}, \mathrm{PhD}, \mathrm{DMSc}$

${ }^{1}$ National Allergy Research Centre, Department of Dermatology and Allergy, Herlev and Gentofte Hospital, University of Copenhagen, 2900 Hellerup, Denmark

${ }^{2}$ Department of Mechanical Engineering, Technical University of Denmark, Lyngby, Denmark

\section{Running head}

Fidget spinners and metal release

Word count: 1153

Tables (supplementary): 2

Figures (supplementary): 3

\section{Corresponding author}

Malin Glindvad Ahlström

National Allergy Research Centre

Department of Dermatology and Allergy

Herlev and Gentofte Hospital

University of Copenhagen

DK-2900 Hellerup

Denmark

Telephone: (0045) 38677310

E-mail: malin.glindvad.ahlstroem.01@regionh.dk

Conflict of interests

None of the authors declare any conflict of interests.

\section{Key words}

Fidget spinners, contact allergy, nickel, cobalt, children 


\section{Introduction}

Fidget spinners, toys used by children of school age, became very popular in 2017. During normal play, they are in direct and prolonged contact with the skin on the hands. Fidget spinners may have metals parts and therefore represent a potential source of metal contact allergy and in turn allergic contact dermatitis. The aim of this study was to screen a random selection of fidget spinners on the Danish market for nickel- and cobalt release.

\section{Methods and results}

In July-August 2017, M.G.A. purchased 41 random fidget spinners from a wide variety of stores: toy-stores $(n=10)$, on the internet $(n=10)$, accessory stores $(n=9)$, markets $(n=4)$, bookshops $(n=2)$, Danish discount design chains $(n=2)$, a greengrocer $(n=1)$, a supermarket $(n=1)$, a sports shop $(n=1)$ and a piercing- and tattoo clinic $(n=1)$. No duplicates were purchased. In total, we spent $440 €$ and the price varied from $2.7-23 €$. The dimethylglyoxime (DMG) test and the cobalt spot test were used for screening of nickel- and cobalt release respectively $(1,2)$ by M.G.A. in our laboratory at Department of Dermatology and Allergy in Copenhagen, Denmark. Qualitative analysis with X-ray fluorescence (XRF) (Oxford Instruments, Maxxi 6, 2016, S/N 21G1627, Germany) was performed on 10 spinners with a positive or doubtful spot-test reaction or with a green discoloration with the cobalt spot test was chosen for the qualitative analysis of metal content at the Technical University of Denmark. One aluminium containing spinner was analyzed with a TM3000 Hitachi Tabletop Microscope equipped with a Bruker Nano energy dispersive spectroscopy (EDS) detector (product ID 2107, Serial-no.:0357). All metallic sites considered to be in direct contact with the hands i.e. the center pad (where fingertips are placed) (Fig. S1b), the wings (arms) (Fig. S1b) and the outer bearings of the wings (Fig. S2b) were tested. Further, the center ball bearing (under the center pad) (Fig. S2a) was tested as it was made of metal. Parts that were visibly comprised of plastic were not tested.

The DMG spot test was performed as previously described (3). The result was classified as positive (pink), negative (no colour change) or doubtful (discoloration other than pink). All locations with doubtful reactions were re-tested: a remaining doubtful test reaction was classified as doubtful. The cobalt spot test was performed before the DMG-test to decrease the risk of false-positive reactions (1). In case the cobalt spot test had resulted in a colour change, the fidget spinner was rinsed with tap water before DMG-testing.

The cobalt spot test was prepared at Technical University of Denmark as previously described (1). The fidget spinners were placed on a nonwoven swab (Curi. Med, Abena) and approximately $50 \mathrm{~mL}$ of cobalt spot test was poured over them and the result of the test was read after approximately 20 minutes. Further, metal parts that were not considered to be in direct contact with the swab (such as the center ball bearing) were tested with one drop of the cobalt spot test on a cotton stick and rubbed for 30 seconds (1). The test was classified as positive (orange-red), negative (yellow) or doubtful (light brown to rust-like).

Spot test results are presented in Table S1 and qualitative analysis of 10 spinners are presented in Table S2. The DMG test was positive for one (3.6\% Cl: 0.2-20.2), and doubtful for two of 28 (7.1\% Cl:1.3-25.0) tested center pads. EDS of the DMG-positive center pad verified a content of $0.9 \%$ nickel, and XRF analysis of the two doubtful DMG spot test reactions showed a content of $0.5 \%$ and $4.7 \%$ nickel, respectively. None of the center pads were positive for cobalt. Unexpectedly, 2 of the center pads contained high amounts of lead (Table S2).

Three spinners had DMG-positive wings (Fig. S1a) and additional qualitative analysis of these spinners confirmed high nickel content (36.6-43.5\%). One outer bearing of the wing had a doubtful DMG-spot test reaction, but was found not to contain nickel by XRF. Qualitative analysis of the DMG spot test negative wings of one spinner showed that it contained brass with a plated layer of nickel and then a physical vapour deposition (PVD) coated layer of titanium (Fig. S1b). A cross section through the wings of this spinner revealed that it also contained lead. Qualitative analysis of the wings of one spinner, with a doubtful cobalt spot test 
confirmed that it contained $0.8 \%$ cobalt. Further, 8 fidget spinners were tested positive with the DMG spot test at the center ball bearing, a site probably rarely in direct contact with the skin (Table S2).

Different nuances of brown (light brown to rust like) emerged with the cobalt spot test for 19 spinners. The light brown nuances appeared when the metal contained copper or nickel (Fig. S2c, Fig. S3c). The darker brown colour from one spinner was caused by rust formation (Fig. S2b).

Further, a green discoloration with varying intensity appeared in 33 of the 41 fidget spinners corresponding to metal parts (Fig. S2a-c, S3c). Qualitative analysis showed a high content of iron corresponding to these parts (Table S2). The green and brown colour occurred from the same metal parts of several spinners (Fig. $\mathrm{S} 2 \mathrm{~b})$.

\section{Discussion}

In this study of 41 fidget spinners, we found nickel release by the DMG-spot test from four and cobalt release by the cobalt spot test from none of the metallic parts expected to have skin contact during normal play. Further qualitative analysis confirmed nickel content (0.9\%-43.5\%) in the four DMG-positive spinners, and on the surface of one center pad with a doubtful DMG spot-test (4.7\%). Cobalt was found in a content of $0.8 \%$ on the surface of the wings of one spinner. Nickel release was detected both from center pads, which is in direct contact with the skin during play, and from the wings which we expect to have some skin contact.

Qualitative analysis of a selection of 10 spinners revealed the use of chromium and lead in some spinners. Lead content of 1.4-2 wt\% was found in two center pads and in the wings of one spinner, and was probably intentionally added as it is known to ease brass machinability. The DMG spot-test was positive for one center pad that was found mainly to be composed of aluminum. A thin layer of nickel remaining on aluminum after surface treatments has previously been described for products such as computers $(4,5)$.

The cobalt spot test is relatively new (1) and interference with other metals or materials has been reported $(8,9)$. In this study we found a green and/or rust-like discoloration in metal parts with high iron contents and light brown discoloration due to nickel or copper. Our results confirm the usefulness of the cobalt spot-test, however due to the risk of misinterpretation by rust formation or interference with other released metal ions it is important also to perform follow up studies of spot test analysis with quantitative qualitative analysis techniques as e.g. XRF analysis.

We conclude that some fidget spinners may elicit nickel- or cobalt allergic contact dermatitis.

\section{Acknowledgement}

The authors would like to thank multimedia designer Anna Bünning Olsson for assisting with the setup of figures. 


\section{Legends}
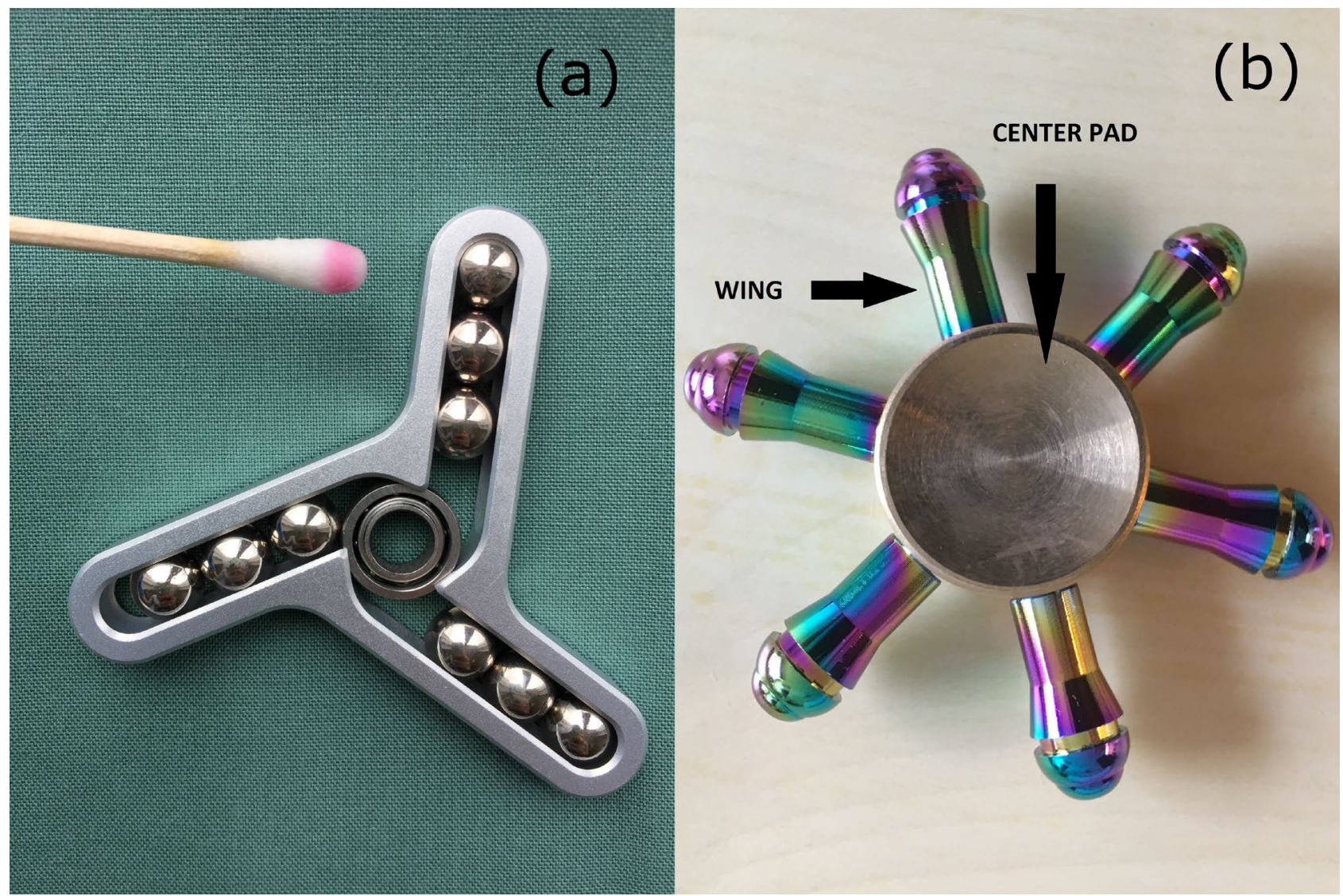

Figure S1 a) A positive dimethylglyoxime (DMG) test reaction for the metallic balls of the wings of a fidget spinner. Qualitative analysis indicated that it is a nickel plated steel ball. b) Photo of a spinner with high concentrations of lead in the center pad and in the wings.

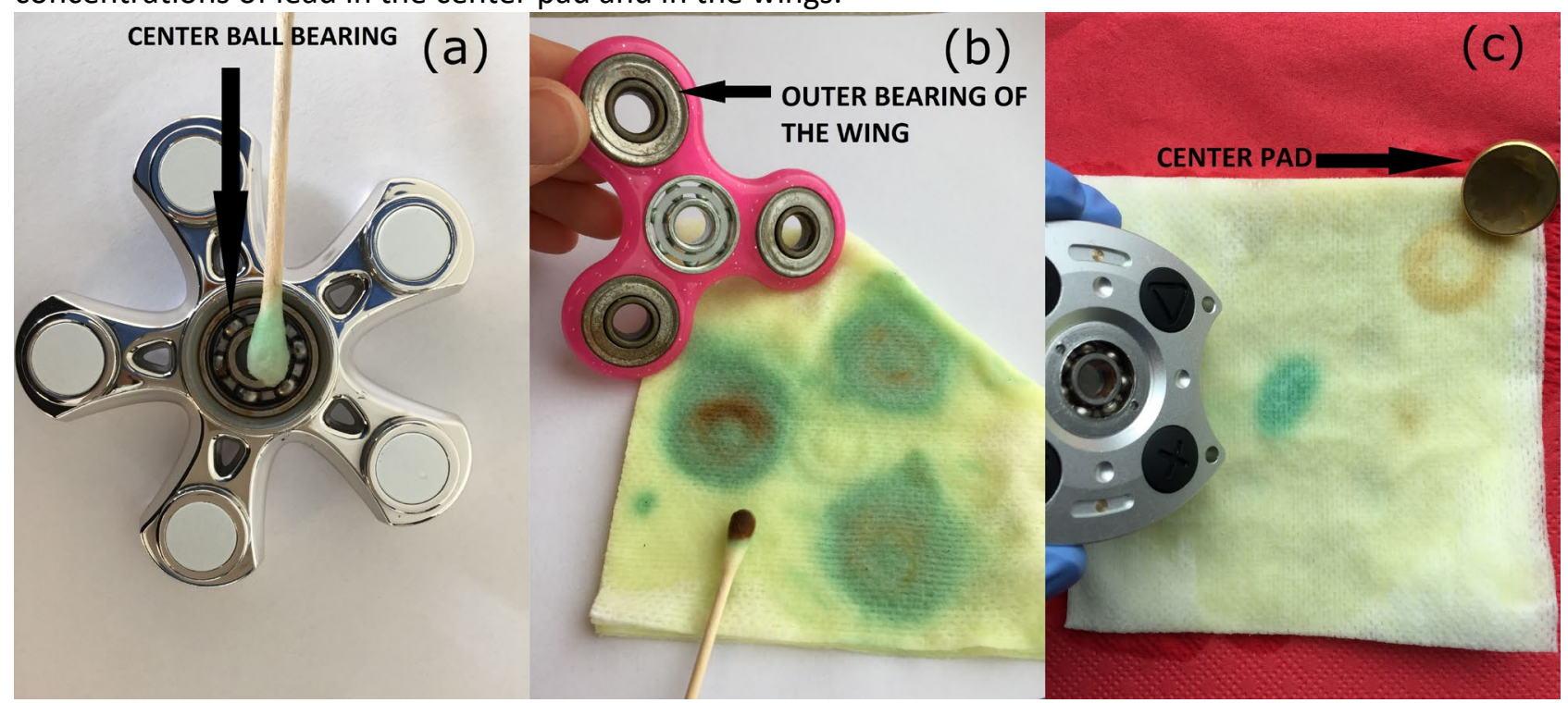

Figure S2 a) Cobalt spot test of the center ball bearing resulting in green discoloration, believed to be caused by iron release. Qualitative analysis showed chromium containing iron alloy, indicating that the ball could be made of DIN $100 \mathrm{Cr} 6$ - a conventionally used ball bearing steel type.

b) Cobalt spot test resulting in green and rust-like discoloration (also shown on a cotton stick) of the metal parts of three outer bearings of the wings. Qualitative analysis confirmed high amounts of iron being present. 
c) Cobalt spot test resulting in light brown discoloration from the center pad (removed), believed to be caused by copper ion release as the qualitative analysis suggests the center pad to be made of brass.

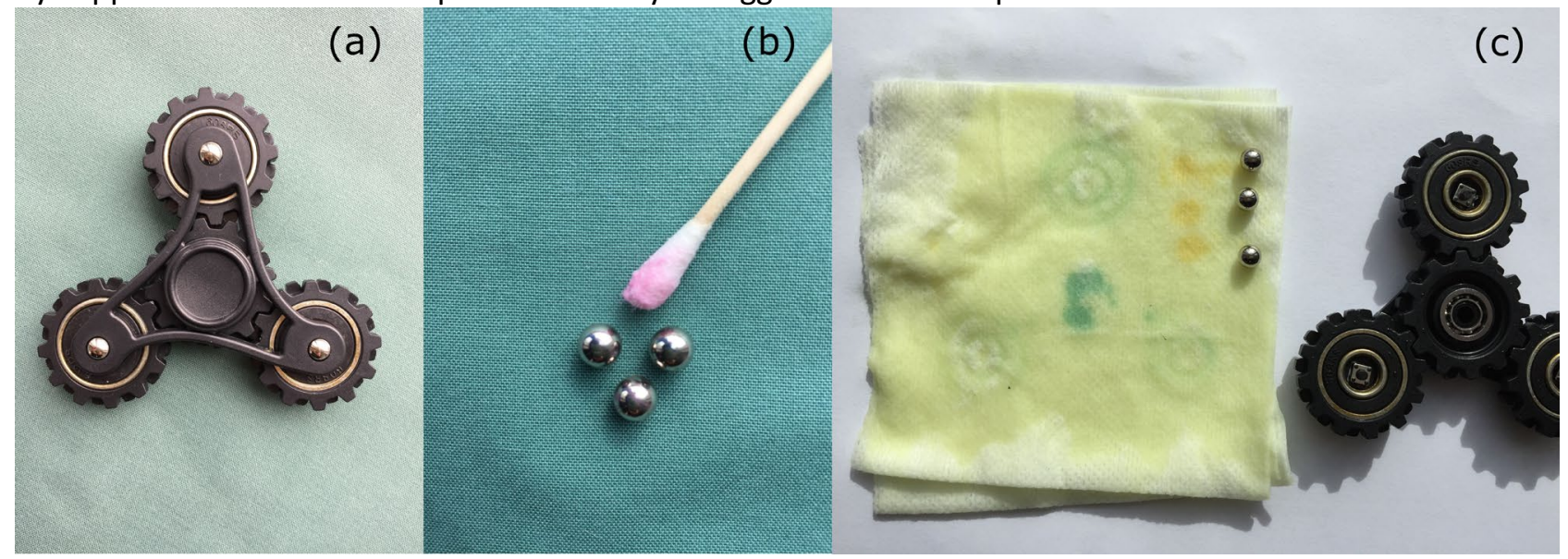

Figure S3 a) A fidget spinner before dismantling b) Metal balls from the wings are nickel plated iron balls which were positive with the DMG spot test and c) light brown with the cobalt spot test. Further, the center ball bearing and the metal of the three outer bearings of the wings resulted in green discoloration.

Table S1) Spot test results.

\section{Tabel 1. Spot test results.}

\begin{tabular}{|c|c|c|c|c|c|}
\hline & $\begin{array}{l}\text { Part of fidget } \\
\text { (\%) }\end{array}$ & pinner, $n$, & & & \\
\hline DMG test result & $\begin{array}{l}\text { Center pad, } \\
n=28\end{array}$ & $\begin{array}{l}\text { Wing, } \\
n=41\end{array}$ & $\begin{array}{l}\text { Centre } \\
\text { bearing, } n=40 \text { \# }\end{array}$ & Cobalt test result & $n=41$ \\
\hline positive & $1(3.6)$ & $3(7.3)$ & $8(20.0)$ & positive & $1(2.4)$ \\
\hline negative & $25(89.3)$ & $37(90.2)$ & $32(80.0)$ & negative & $21(51.2)$ \\
\hline doubtful & $2(7.1)$ & $1(2.4)$ & 0 & doubtful & $19(46.3)$ \\
\hline & & & & green & $\begin{array}{l}33 / 41 \\
(80.5)\end{array}$ \\
\hline \multicolumn{3}{|c|}{ * Buttons made by plastic were not DMG-tested } & & & \\
\hline \multicolumn{5}{|c|}{ \# In one occasion the button could not be removed to uncover the centre bearring } & \\
\hline
\end{tabular}

Table S2) Full test result list for 10 fidget spinners, tested by DMG- and cobalt spot test and XRF analysis

\begin{tabular}{|c|c|c|c|c|c|c|c|c|c|c|c|c|c|}
\hline & & & & & $\begin{array}{c}\text { XRF } \\
\text { analysis } \\
\text { of } \\
\text { elements } \\
\text { [wt.\%] }\end{array}$ & & & & & & & & \\
\hline Nr. & Part of spinner & Figure & $\begin{array}{c}\text { DMG } \\
\text { test }\end{array}$ & Cobalt test * & $\%$ Co & $\% \mathrm{Cr}$ & $\% \mathrm{Cu}$ & $\begin{array}{l}\% \\
\mathrm{Fe}\end{array}$ & $\begin{array}{l}\% \\
\mathrm{Ni}\end{array}$ & $\begin{array}{r}\% \\
\mathrm{~Pb}\end{array}$ & $\begin{array}{c}\% \\
\text { Sn }\end{array}$ & $\begin{array}{r}\% \\
\mathrm{Zn}\end{array}$ & $\begin{array}{l}\% \\
\mathrm{Ti}\end{array}$ \\
\hline 1 & Wing & $1 a$ & pos & neg & 0,2 & 0,0 & 0,0 & 56,3 & 43,5 & 0,0 & 0,0 & 0,0 & 0,0 \\
\hline 2 & Center pad & $1 b$ & doubtful & light brown & 0,0 & 0,1 & 55,8 & 0,5 & 0,5 & 1,4 & 0,0 & 41,8 & 0,0 \\
\hline 2 & Wing surface & $1 b$ & neg & brown & 0,0 & 1,1 & 80,4 & 0,0 & 0,0 & 0,0 & 0,0 & 3,2 & 1,4 \\
\hline
\end{tabular}




\begin{tabular}{|c|c|c|c|c|c|c|c|c|c|c|c|c|c|}
\hline 2 & $\begin{array}{l}\text { Wing } \\
\text { crosssection }\end{array}$ & $1 b$ & $\begin{array}{l}\text { not } \\
\text { tested }\end{array}$ & not tested & 0,0 & 0,0 & 55,8 & 0,6 & 0,3 & 2,1 & 0,0 & 41,1 & 0,0 \\
\hline 3 & $\begin{array}{l}\text { Center ball } \\
\text { bearing }\end{array}$ & $2 a$ & neg & green & 0,1 & 1,3 & 0,0 & 98,5 & 0,0 & 0,0 & 0,0 & 0,0 & 0,0 \\
\hline 4 & Outer bearing & $2 b$ & neg & $\begin{array}{l}\text { brown and } \\
\text { green }\end{array}$ & 0,2 & 0,0 & 0,1 & 88,1 & 0,0 & 0,0 & 0,0 & 11,7 & 0,0 \\
\hline 5 & Ball on wing & $2 c$ & pos & neg & 0,2 & 0,0 & 0,0 & 60,9 & 38,9 & 0,0 & 0,0 & 0,0 & 0,0 \\
\hline 5 & Center pad & $2 c$ & neg & light brown & 0,0 & 0,1 & 56,0 & 0,3 & 0,4 & 2,0 & 0,0 & 41,2 & 0,0 \\
\hline 5 & $\begin{array}{l}\text { Center ball } \\
\text { bearing }\end{array}$ & $2 c$ & neg & green & 0,1 & 1,3 & 0,1 & 98,5 & 0,0 & 0,0 & 0,0 & 0,0 & 0,0 \\
\hline 6 & Ball on wing & 3 & pos & light brown & 0,2 & 0,0 & 0,0 & 63,2 & 36,6 & 0,0 & 0,0 & 0,0 & 0,0 \\
\hline 7 & $\begin{array}{l}\text { Center ball } \\
\text { bearing }\end{array}$ & & neg & $\begin{array}{l}\text { pos and } \\
\text { green }\end{array}$ & 0,0 & 1,3 & 0,1 & 98,6 & 0 & 0 & 0 & 0 & 0,0 \\
\hline 8 & Center pad & & doubtful & light brown & 0,0 & 0,0 & 77,9 & 0,0 & 4,7 & 0,0 & 0,7 & 16,7 & 0,0 \\
\hline 8 & Wing & & neg & pos & 0,8 & 0,0 & 65,1 & 0,0 & 0,0 & 0,0 & 0,4 & 33,7 & 0,0 \\
\hline 9 & Outer bearing & & doubtful & green & 0,1 & 0,0 & 0,0 & 76,0 & 0,0 & 0,0 & 0,0 & 23,9 & 0,0 \\
\hline $10 *$ & Center pad & & pos & neg & 0,0 & 0,0 & 0,0 & 0,0 & 0,9 & 0,0 & 0,0 & 0,0 & 0,0 \\
\hline
\end{tabular}




\section{References}

1 Thyssen JP, Menné T, Johansen JD, et al. A spot test for detection of cobalt release- early experience and findings. Contact Dermatitis 2010: 63: 63-9.

2 Thyssen JP, Skare L, Lundgren L, et al. Sensitivity and specificity of the nickel spot (dimethylglyoxime) test. Contact Dermatitis 2010: 62: 279-88.

3 Thyssen JP, Menné $T$, Lidén $C$, et al. Excessive nickel release from earrings purchased from independent shops and street markets - a field study from Warsaw and London. J Eur Acad Dermatology Venereol 2011: 25: 1021-6.

$4 \quad$ Midander K, Hurtig A, Borg Tornberg A, Julander A. Allergy risks with laptop computers - nickel and cobalt release. Contact Dermatitis 2016: 74: 353-9.

5 Jensen $P$, Jellesen MS, Moller $P$, et al. Nickel allergy and dermatitis following use of a laptop computer. J Am Acad Dermatol 2012: 67: 170-1.

6 Thyssen JP, Menné T, Johansen JD. Nickel release from inexpensive jewelry and hair clasps purchased in an EU country - Are consumers sufficiently protected from nickel exposure? Sci Total Environ 2009: 407: 5315-8.

7 Bruze M, Hamada H, Dahlin J, et al. A positive cobalt spot test falsely indicating an occupational allergic contact dermatitis caused by cobalt. Contact Dermatitis 2013: 69: 172-5.

8 Thyssen JP, Johansen JD, Menné T, Jellesen MS. Does cobalt spot testing of copper items result in false-positive test reactions? Contact Dermatitis 2013: 69: 387-8.

9 Reshetnyak E, Ivchenko N, Nikitina N. Photometric determination of aqueous cobalt (II), nickel (II), copper (II) and iron (III) with 1-nitroso-2-naphthol-3,6-disulfonic acid disodium salt in gelatin films. Open Chem 2012: 10: 1617-23. 